\title{
A Decision Making Framework for SOA Adoption in e-Banking: A Case Study Approach
}

\author{
Nikolaos Basias, Marinos Themistocleous, and Vincenzo Morabito
}

\begin{abstract}
E-banking grows rapidly due to the numerous potential benefits associated with it and integration is one of the most important challenges for e-banking success. In addressing integration issues, SOA has emerged and adopted by many banks. Nevertheless, numerous banks fail to achieve successful SOA adoption for various reasons. One of the main reasons is attributed to the lack of a methodological framework that would (a) explain factors affecting SOA adoption in e-banking and (b) define the SOA adoption process in e-banking. Such a framework might be used by banks as a decision making tool to support the mechanism of effective decision-making. As a result the aim of this paper is: (a) to fill in this literature void by proposing a decision making framework for SOA adoption in e-banking and (b) to test it through a case study approach in the practical arena. In doing so, this paper extends the body of knowledge and provides new insights related to SOA adoption in e-banking.
\end{abstract}

Index Terms-E-banking, IT adoption, influential factors, SOA.

\section{INTRODUCTION}

Information Technology (IT) adoption is considered as a key driver for bank's business processes and services automation and integration. According to recent surveys worldwide IT spending reach approximately US $\$ 3.6$ trillion in 2012 [1] and total bank IT spending across North America, Europe, and Asia-Pacific grows to US\$173.3 billion in 2012 [2]. In addition, the rise of Internet and e-business use, along with improved technology and online security of transactions and sensitive information, are the core reasons for penetration of e-banking. The percentage of individuals using the Internet continues to grow worldwide and 2.3 billion people were online by 2011. In developed countries $70 \%$ of the total households had Internet access by 2011 . Total mobile-cellular subscriptions reached almost 6 billion by end 2011, corresponding to a global penetration of $86 \%$ [3]. Internet and mobile phone users are important target groups related to improved and new e-banking services and banks seek for secure, advanced integrated IT infrastructures to provide efficient e-banking services to them.

Currently, the one third of Europeans uses e-banking with estimates predicting an average adoption rate of $60 \%$ in the EU by 2020 [4]. This indicates that e-banking is an interesting fast growing area. In addition, international organizations highlight the importance of e-banking matters, publishing surveys which underline the potential of

Manuscript received September 10, 2013; revised November 15, 2013.

Nikolaos Basias is with the University of Piraeus, Greece (e-mail: basias@unipi.gr). e-banking on greater financial access [4], [5]. Service Oriented Architecture (SOA) is another key issue of high importance [6]-[9]. Integration issues are always a concern for banks with SOA promising solutions to integration problems. SOA improves efficiency and reduces operating costs by promoting a faster flow of information throughout banks. Furthermore, SOA optimizes the business processes and adds corporate business value. However, many banks fail to achieve the benefits from integration efforts in e-banking for various reasons [10] and organizations are confused over how to adopt SOA successfully [9]. One of the primary reasons why organizations fail to achieve successful SOA adoption is attributed to a lack of a decision making framework for SOA adoption [11]. For this reason, the absence of a methodological framework that would explain SOA adoption in e-banking forms an important research problem that requires deeper investigation. Such a framework is essential for managers in banks to make robust decisions for SOA adoption in e-banking, realizing benefits, barriers, risks and costs associated with it.

This paper is organized as follows. Section II introduces the proposed decision making framework for successful SOA adoption in e-banking. Section III briefly describes the research methodology used for this research. Then, Section IV presents empirical data from a case study and Section V discusses findings. Section VI presents lessons learned and finally Section VII presents some conclusions and our future research agenda.

\section{A DECISION MAKING FrAMEWORK FOR SOA AdOPTION IN E-BANKING}

To situate the current study and to provide context related to SOA adoption in e-banking we review the normative literature. The literature review is conducted through an extensive search on books, journals, conference proceedings and working papers published after 2005 using libraries and database search engines like AISel, IEEE Xplore, ProQuest, Science Direct, Google Books and Google Scholar. In a first step we use keywords like: "Integration in e-banking" and "SOA adoption in e-banking" and no matches are found for the criteria specified. We request for related literature to SOA adoption in e-banking via AIS world mailing list without any success.

For that reason, we use keywords like: "e-banking" and "SOA adoption" to investigate this area and to identify and select from a large amount of hits 195 literatures for deeper investigation and analysis. A review with a procedure outlined by Webster \& Watson [12] downsize literature to 88 e-banking or SOA literatures, used in this research, 
todescribe, summarize, evaluate and clarify the adoption of SOA in e-banking.

The critical analysis of the literature review indicates that: (a) integration is one of the most important factors for e-banking success and banks continue to face integration problems related to e-banking [10] , [13], (b) SOA might be a solution for banks to solve integration problems related to e-banking [13], [14], (c) one of the main reasons why banks often fail to achieve the benefits from integration efforts in e-banking is the lack of a methodological framework [15], (d) there is no study on analyzing the critical success factors of SOA adoption in e-banking, (e) there is no methodological framework to explain critical success factors affecting SOA adoption in e-banking, (f) the analysis of models and frameworks indicates that several factors and classifications of factors are not similar among researchers, $(\mathrm{g})$ while some adoption issues are relevant for any organization, others depend on the industry and type of organization and some of these differences may be pertinent to the adoption of SOA in e-banking, (h) e-banking has different requirements and business drivers and may follow a different adoption path, (i) the SOA adoption path in e-banking is not clearly defined and there is a confusion about the SOA adoption content and (j) a methodological framework that explain critical success factors for SOA adoption in e-banking is essential for banks to make right decisions [16].

This paper concentrates on the following two interesting research questions:

R.Q.1: Which influential factors are crucial for the decision making process for successful SOA adoption in e-banking?

R.Q.2: What are the dimensions and stages of SOA adoption in e-banking?

Based on an extensive critical review we build a decision making framework for SOA adoption in e-banking. The conceptual framework illustrates the relationship between e-banking and SOA adoption, providing a research framework for examining factors affecting SOA adoption in e-banking. In addition, it illustrates the stages of SOA adoption in e-banking. Our classification forms the framework for the methodology of research presented in this paper. In order to classify influential factors we espouse our taxonomy presented in earlier research [16]. Our classification divides factors into four different categories: (a) business factors, (b) technical factors, (c) managerial factors and (d) human factors. We add a human factors category into our framework as: (a) extensive literature review indicates that human factors are crucial in many areas [17] and (b) human factors might be important for SOA adoption in e-banking and need to be investigated. Business factors: (a) barriers, (b) benefits and (c) cost. Human factors: (a) fatigue, (b) staff, (c) stress and (d) resistance to change. Managerial factors: (a) business alignment, (b) communication, (c) goal setting, (d) risk and (e) strategy. Technical factors: (a) IT Infrastructure, (b) security and (c) support from external entities such as vendors and consultants.

The SOA adoption Lifecycle in e-banking implemented in our model has three stages: (a) SOA initiation, (b) SOA planning and (c) decision of SOA adoption. SOA initiation: The SOA initiation phase is the first phase in the project. In this stage a business problem or opportunity related to SOA adoption in e-banking is identified and a business case which provides various solution options is defined. SOA planning: After defining the scope of the SOA adoption project the second stage involve a detailed planning phase that involves: (a) project plan, (b) resource plan, (c) financial plan, (d) quality plan, (e) risk plan, (f) acceptance plan and (g) communications plan. Decision of SOA adoption: The third and last stage refers to the analysis of the previous stages that leads to the decision to adopt or not SOA. The whole proposed decision making framework for SOA adoption in e-banking is illustrated bellow (Fig. 1).

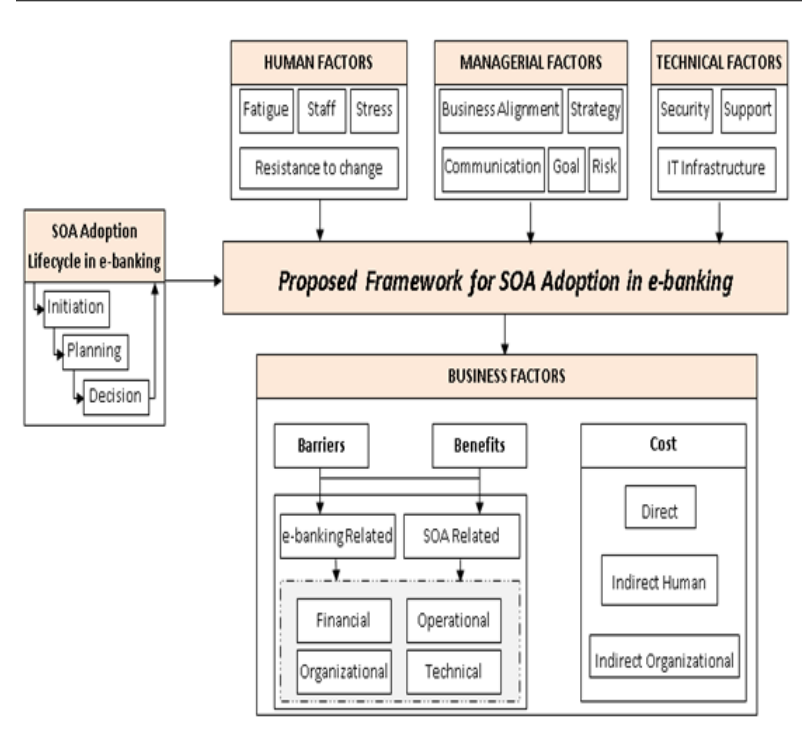

Fig. 1. Decision making framework for SOA adoption in e-banking

The research methodology we choose to test this decision making framework is presented in Section III.

\section{RESEARCH METHODOLOGY}

An exploratory research approach is used in our research. Exploratory research often relies on secondary research such as reviewing available literature related to SOA, or qualitative approaches such as discussions with bank employees, bank management and more formal approaches through in-depth interviews, focus groups, projective methods, case studies or pilot studies. As SOA remains a research area of high importance [6], [9] the qualitative research method seems to be the appropriate approach to investigate and analyze in depth SOA adoption in e-banking [18]. The main focus in qualitative research is to understand explain, explore, discover and clarify situations, feelings, perceptions, attitudes, values, beliefs and experiences. Factors that influence SOA adoption cannot be separated from its organizational, technical and cultural context. Therefore, there is a need for a qualitative research approach that allows understanding the process of SOA adoption and the factors that influence SOA adoption in e-banking.

In this paper a case study strategy is used to test the proposed framework since it seems more appropriate for the banking sector [8]. A case study offers a 'holistic' view of the processes involved, as well as a realisation of the topic under 
research [19]. Baskerville [13] uses a case study approach to study the strategic value of SOA. In their understanding case studies facilitate multi-perspective analyses that lead to a holistic understanding of cultural systems of action, providing the insight that satisfies exploratory questions. Considerable work on SOA takes the form of case studies to identify SOA success [9]. The need for rich empirical data related to factors affecting SOA adoption in e-banking indicates that the use of a case study approach is appropriate, since it allows examining in depth processes. An important aspect of a case study is the use of multiple methods to collect data that leads to obtain rich empirical data for this research.

Data collection methods such as interview, documentation and observation are used in this research. We develop an open/ended questions interview agenda to ensure desired coverage of the areas of enquiry and comparability of information across respondents. Empirical data derived from a case study related to SOA adoption in e-banking are triangulated and then analyzed to draw empirical conclusions. Data triangulation involves using different sources of information in order to increase the validity of a study. The purpose of triangulation in qualitative research is to increase the credibility and validity of the results. The benefits of triangulation include: (a) increasing confidence in research data, (b) creating innovative ways of understanding a phenomenon, (c) revealing unique findings, (d) challenging or integrating theories, and (e) providing a clearer understanding of the problem.

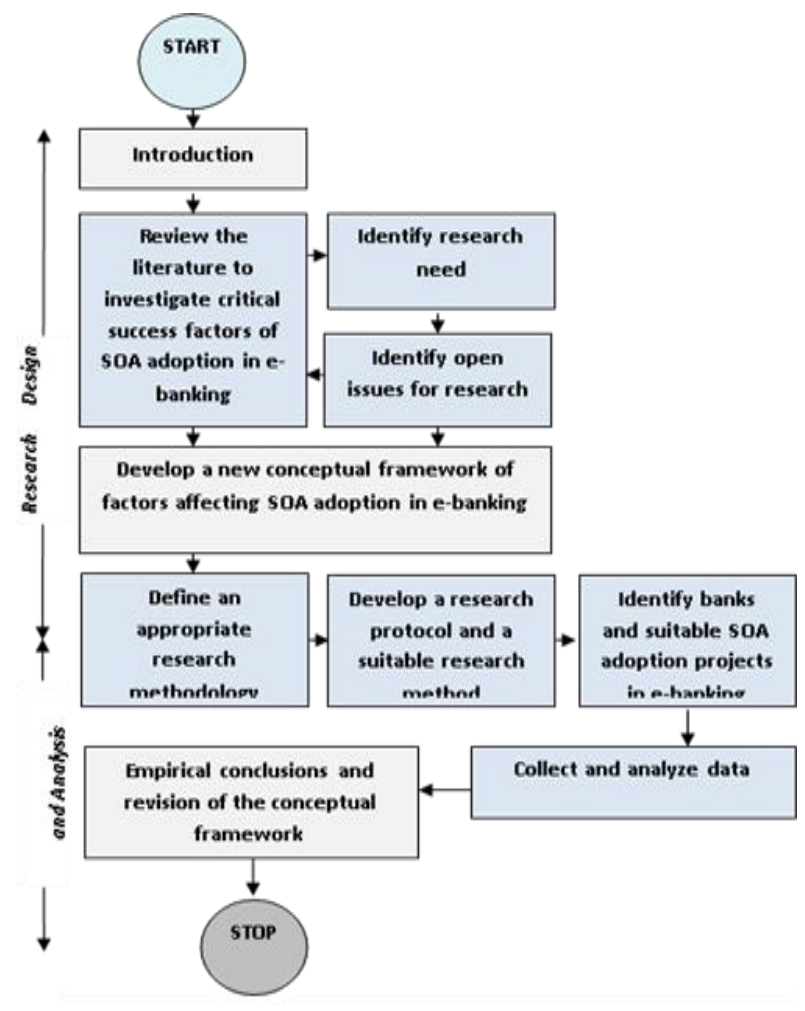

Fig. 2. Research methodology.

The proposed decision making framework of SOA adoption in e-banking is tested through a case study in e-banking. The case study is conducted in a large American bank that had recently decided to adopt SOA in e-banking. The case organization is a bank with more than 4,500 branches and more than 250.000 employees and a presence in circa 100 countries around the globe. The name of the bank is not revealed due to confidentiality restrictions. Thus, we use the name Lambank to refer to the Large American Bank under investigation. We collect applicable documents and records during a period of 7 months and we interviewed 4 professionals who played a key role in a project related to SOA adoption in e-banking. Specifically, we interviewed (a) the SOA project manager, (b) an IT manager involved in this project, (c) a manager from business and (d) a member of the IT strategy board. Telephone, Skype and e-mail were used to clarify unclear issues in a later stage. The research methodology used in this research is illustrated analytically in Fig. 2.

Empirical data and findings are presented in the next Section.

\section{EMPIRICAL CASE DATA}

Lambank is a leading global financial services company with 200 million customer accounts and does business in more than 100 countries, providing customers, corporations, governments and institutions with a broad range of financial products and services, including consumer banking and credit, corporate and investment banking, securities brokerage, wealth management and e-banking. Lambank is embarking on a multi-year, multi-billion dollar IT investment to integrate its consumer branches and products all over the world. A part of this project refers to integration in e-banking.

As stated from a member of the IT strategy board "We have changed completely our strategy. We do not want any more a strategy that is led by products. Lambank has 15 to 20 different customer bases in nearly every country in which it operates. For instance, the credit card portfolio division has a different customer base than the mortgage portfolio division and the two don't necessarily communicate with each other. When this project is complete, there will be only one single customer base all over the world".

According to a manager from business "Integration leads to faster and better services to our clients. If we are providing fast the right solutions to their financial needs the customers will actually honor us. Revenue per client will actually go up and our origination costs will go down."

Lambank faces integration problems and needs complete views of each customer, regardless of products or contact, whether ATM, Internet, mobile or branch. For that reason, Lambank is in the middle of stitching together its disparate technology systems, spending about $\$ 950$ million. As a result, expenses have risen more than 9 per cent and are expected to remain high until the project is completed. The goal is the full integration of all consumer banking operations across the world, a massive unified system that emphasizes new types of online and mobile banking.

As stated from an IT manager "E-banking is of high importance for our bank. For that reason Lambank unveiled a new online experience for its customers. The new e-banking platform offers a dramatically streamlined design, an intuitive user experience and brings simplicity, flexibility, and control to everyday household financial management". The new e-banking platform offers new, advanced features to 
help customers meet their financial goals, including personal finance tools, customized charts and graphs and the ability to analyze multiple accounts, including from third-party retailers, utilities or other financial institutions. Lambank offers online clean pages and simplified menus to make it easier for customers to find exactly what they need. The bank also completely rewrote all product and services information on the site, replacing technical, industry-specific terminology with a more relaxed and consumer-friendly tone.

E-banking now offers a robust suite of personal finance tools to help customers to take control of their financial futures. Customers can also choose to integrate third-party accounts from more than 10,000 websites of retailers, utilities and other financial institutions, providing an easier way to plan and analyze all finances from a single destination. Integrated into the e-banking platform, advanced personal finance management features allow users to view information and take actions that will make managing their finances easier.

As stated from the SOA project Manager "New and improved e-banking services bring out integration problems. For that reason our bank runs a major project on a global basis to integrate platforms via ESB Technologies and to solve integration problems. As a large bank we suffer from a large number of supporting systems and SOA adoption is a solution for channel and system integration. System integration because of the diverse existing IT infrastructure and channel integration to better utilize software components across channels". Empirical data revealed from this case study confirm that SOA provides Lambank with robust, resilient IT architecture it needs to grow. SOA achieves speed-to-market and optimizes customer service. Furthermore, it provides a platform to help meet compliance requirements and assure security and integrity of information assets.

\section{FINDINGS}

Empirical data revealed from this case study confirm that managerial factors as (a) strategy and (b) goal are important factors for successful SOA adoption in e-banking. As stated from a top manager: "SOA is relatively new and as a result, there can be a lack of understanding among senior management about its potential and implications. It is important for Lambank to have a clear strategy driven from the top. Such strategy should take into account the effects of e-banking and should be clearly disseminated across business, supported by a clear business plan with an effective monitoring of performance........." According to this case study perceived future prospect was placed among the top factors. Clear goal setting based on business value and a vision for the future are critical to SOA adoption in e-banking All of the interviewees agreed that the main goal for Lambank was to establish through SOA adoption a foundation that will successfully support future business needs for many years.

Furthermore, as factors that influence significantly SOA adoption in e-banking have been reported: (a) SOA best practices, (b) common culture among business, IT and Vendor and (c) perceived future prospect. Related to the staff, (a) talent, (b) expertise and (c) education and training were stated as important influential factors for SOA adoption in e-banking. Moreover, human factors like (a) stress and (b) fatigue are confirmed by this case study but not as significant ones. Resistance to change is confirmed as a significant human factor. Among top factors was placed vendors/consultants support: (a) good communication with vendor, (b) good collaboration with vendor and (c) vendors expertise. Bank employees involved in this project had no experience in SOA adoption and had to work within very tight schedules, without having time to explore new best practices and solutions. To overcome these problems, Lambank collaborated closely with the Vendor. The above factors were reported by interviewees and the existence was observed.

In addition, empirical findings revealed that IT infrastructure is an important influential factor and the reason is that SOA adoption is based on systems types and existing IT infrastructure. According to the project manager "Lambank uses a complex IT infrastructure to run its operations and IT infrastructure complexity is frequently cited as a reason for failure in SOA projects......" Service composition is highly complex and often includes transactions, unit-of-work boundaries, error handling, security and propagation of credentials, quality of service and aggregation of business logic. Moreover, one of the main challenges in e-banking is how to predict and manage the volume of customers. Lambank was concerned about to predict volumes correctly. When a bank has insufficient systems, this can lead (a) to reputational damage, (b) financial damage and (c) compromises in security due to online systems that are insufficient configured or tested to deal with capacity problems. For successful e-banking services, banks need management information to monitor their e-services. For that reason, Lambank established and configured new systems to ensure that sufficient, meaningful and clear information is generated. Such information is particularly important in a field like e-banking. IT is closely related to Business Alignment.

IT and Business Alignment holds a top priority amongst influential factors of SOA adoption in e-banking. IT could not easily follow new business needs. As reported by a senior manager in the IT department "The bank had reached the limits of the infrastructure and when business asked if we can do this we were always responding that there is no easy way to do this..." This led Lambank to consider SOA adoption. Success in SOA adoption requires a purposeful effort to link IT to business processes with a focus on future business process design. Simple connectivity is the most common need and building a scalable infrastructure is a key success factor for SOA adoption in e-banking.

Other important factors that affect SOA adoption in e-banking, reported by interviewees are Security and efficient Risk Management. Security and risks are always concerns for banks. E-banking increases security risks, exposing systems to open and risky environments. The banks need to be proactive in monitoring and managing the security threat. E-banking is often a target for hackers. Lambank are facing security threats such: (a) breaches with serious criminal intent like fraud and theft of commercially sensitive 
or financial information (b) breaches by hackers such deformation of web sites and triggering web sites to crash and (c) failures in systems design. All of these threats have serious legal, financial and reputational implications for banks. Details regarding personal information and data regarding electronic money transactions must be highly secure. For that reason, Lambank uses firewalls and highest levels of encryption to secure e-banking. The bank uses secure layer technology which encrypts all of the information, from a customer logging in to feedback to the customer. Although, SOA creates an open framework, it can also enhance the security of your data and systems as you implement security as a service. It is important to establish a comprehensive view of security and delegate specific requirements to appropriate points. Lambank needed to leverage middleware services to meet key infrastructure requirements for security, logging and monitoring.

From the analysis of the empirical data (a) return on Investment (ROI), (b) benefits, (c) barriers and (d) costs were also identified as factors affecting SOA adoption. These factors are closely related together. For Lambank there was a need to measure the benefits and the costs of SOA adoption related to e-banking. The bank tried to measure possible benefits from reduced downtime, improved time to market, improved customer service and reduced IT costs since SOA adoption and the total possible investment for SOA adoption in hardware, software, requirements, annual maintenance, customization, training and consulting. As stated from the project manager: "ROI is a useful indicator but it is difficult to measure all the benefits and costs for an IT project like SOA adoption in e-banking. There are often deviations from budget planning to SOA adoption.........."

Another key factor to achieve benefits from SOA adoption in e-banking is SOA governance. All interviewees reported that effective SOA governance helped the bank adopting SOA. SOA governance supports the bank among others to clearly define: (a) roles and responsibilities, (b) the quality of services and (c) the service agreements, leading to an extendable and scalable SOA solution.

According to the SOA adoption lifecycle in e-banking our proposed three stages (a) SOA initiation, (b) SOA planning and (c) SOA decision are confirmed. Lambank gives importance related to SOA adoption in e-banking to (a) identify business problem or opportunity related to SOA adoption, (b) outline objectives, structure and scope of SOA adoption in e-banking, (c) appoint project manager, (d) tools and vendor selection, (e) outline activities, tasks, dependencies and timeframes, (f) listing labor, equipment and materials required, $(\mathrm{g})$ identifying products to be sourced from external suppliers, (h) business paper presentation to top management and (i) decision over SOA adoption or not in e-banking. Lessons learned from this case study are presented in Section VI.

\section{LESSONS LEARNED}

Lesson 1: The case findings disclose that the proposed decision making framework can be used by banks for successful SOA adoption in e-banking. The use of such a framework may help banks to avoid problems related to SOA adoption, realizing factors, benefits, barriers, costs and the SOA adoption lifecycle in e-banking.

Lesson 2: The case analysis indicates some new crucial factors as SOA best practices, Common Culture and SOA Governance related to SOA adoption in e-banking. For that reason there is a need for further research in this area.

Lesson 3: Not all the factors have the same value and most of the individual factors are not independent. Business and managerial factors are more important than technical and human factors and the impact of one factor to the other should be studied.

Lesson 4: The proposed decision making framework provides new insights related to (a) factors affecting SOA adoption in e-banking, (b) classification of factors affecting SOA adoption in e-banking and (c) SOA adoption lifecycle in e-banking and clarify much of the confusion in this area.

\section{CONCLUSIONS AND FutURE RESEARCH AGENDA}

E-banking spreads rapidly all over the globe and most banks offer multiple e-banking products and services because of the numerous potential benefits associated with it. At the same time, e-banking brings up unique types of challenges related to channel, data, application and system integration. Integration is one of the most crucial factors for e-banking success and banks seek for robust IT practices and secure integration solutions such SOA in order to make e-banking more reliable and popular. However, many banks fail to achieve the benefits from integration efforts in e-banking for various reasons. The key reason why organizations fail to achieve the benefits from SOA adoption is attributed to a lack of a framework, taking multiple crucial factors into account. Such a decision making framework is essential for banks to make robust decisions related to SOA adoption in e-banking, realizing benefits, barriers, risks, costs and changes associated with it.

The Lambank case confirms the importance of the 15 influential factors in our model for successful SOA adoption in e-banking. The case also reveals new factors as: (a) SOA best practices, (b) SOA governance and (c) common culture.

In addition, the SOA adoption lifecycle in e-banking proposed in our model was confirmed and clarify much of the confusion in this area. We are planning (a) to test again this decision making framework for SOA adoption in e-banking through a new recent case study related to SOA adoption in e-banking in another bank (b) to compare the findings and (c) to revise the decision making framework.

\section{REFERENCES}

[1] Gartner. (2012). Worldwide IT spending on pace to surpass \$3.6 trillion in 2012. [Online]. Available: http://www.gartner.com

[2] Celent. (2012). IT spending in banking: A global perspective. [Online]. Available: http://www.celent.com

[3] International Telecommunication Union. (2012). Key statistical highlights: ITU data release. [Online]. Available: http://www.itu.int

[4] Deutsche Bank Research. (2010). Online banking and research: The state of play in 2010. [Online]. Available: http://www.dbresearch.de

[5] World Bank. (2008). Banking on mobiles: Why, How, for whom? [Online]. Available: http://www.cgap.org

[6] H. Luthria and F. Rabhi, "Service oriented computing in practice -An agenda for research into the factors influencing the organizational adoption of service oriented architectures," Journal of Theoretical and Applied Electronic Commerce Research, vol. 4, no. 1, pp. 39-56, 2009. 
[7] E. Marks, Service-Oriented Architecture (SOA) Governance for the Services Driven Enterprise, Wiley, 2008.

[8] J. Eckert, N. Repp, M. Bachhuber, and R. Steinmetz, "The implementation of SOA architectures in the german banking industry," in Proc Fifteenth Americas Conference on Information Systems (AMCIS 2009), August 6-9 2009, San Francisco, California.

[9] L. J. Hoon, S. H. Jung, and K. K. Kyu, "Critical success factors in SOA implementation: An exploratory study' information systems management," Information Systems Management, vol. 27, no. 2, pp. 123-145, 2010.

[10] M. Shah, A. Braganza, and V. Morabito, "A survey of critical success factors in e-banking: An organisational perspective," European Journal of Information Systems, vol. 16, pp. 511-524, 2007.

[11] N. Basias, M. Themistocleous, and V. Morabito, "Influential factors of SOA adoption in e- banking," in Proc. European, Mediterranean and Middle Eastern Conference on Information Systems, June 6-7, 2012, Munich, Germany.

[12] J. Webster and R. T. Watson, "Analyzing the Past to prepare for the future: Writing a literature review," MIS Quarterly, vol. 26, 2002.

[13] R. Baskerville, M. Cavallari, K. Madsen, J. Heje, M. Sorrentino, and F. Virili, "The strategic value of SOA: A comparative case study in the banking sector," Int. J. Information Technology and Management, vol. 9 , no. $1,2010$.

[14] M. Rosen, B. Lublinsky, K. T. Smith, and M. J. Balcer, Applied SOA. Service-Oriented Architecture and Design Strategies, Wiley Publishing 2008
[15] J. P. Schonewille, "Integration process factors and effects," in Proc. Sixteenth Americas Conference on Information Systems (AMCIS 2010), August 12-15, 2010, Lima, Peru.

[16] N. Basias, M. Themistocleous, and V. Morabito, "SOA adoption in e-banking," Journal of Enterprise Information Management, vol. 26, no. 6, 2013.

[17] Stamina $-B P M$, Training for the PBM Industries, $1^{\text {st }}-3^{\text {rd }}$ June 2011 , Athens, Greece.

[18] M. B. Miles and A. M. Huberman, Qualitative Data Analysis SAGE, Publications, 1994

[19] R. K. Yin, Applications of Case Study Research, SAGE Publications 2011.

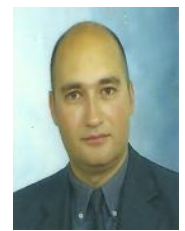

Nikolaos Basias is a research associate and a Ph.D candidate at the University of Piraeus in Greece. In the past, he was a Scientific Collaborator at the Greek Parliament and he worked efficient as a Supervisor in multiple successful multinational companies and in significant large global projects. His main research interests involve E-business, E-banking, Information Systems Management, Integration and Project Management. 